\title{
Full slenderness range DSM approach for stainless steel hollow cross-sections
}

I. Arrayago ${ }^{\text {a }}$, K.J.R. Rasmussen ${ }^{\mathrm{b}}$ and E. Real ${ }^{\mathrm{a}}$

${ }^{a}$ Department of Civil and Environmental Engineering, Universitat Politècnica de CatalunyaBarcelonaTech, Barcelona, Spain.itsaso.arrayago@upc.edu, esther.real@upc.edu

${ }^{\mathrm{b}}$ School of Civil Engineering, The University of Sydney, NSW 2006, Australia. kim.rasmussen@sydney.edu.au

\section{ABSTRACT}

This paper studies the cross-sectional behaviour of austenitic, ferritic and duplex stainless steel hollow sections subjected to several loading conditions and presents a full slenderness range DSM approach for the prediction of cross-sectional strengths. Pure compression, pure bending moment and combined uniaxial bending and compression loading resistances are predicted using the same strength curve, which is based on experimental data gathered from the literature and ultimate strengths generated through parametric studies. The proposed approach is applicable to slender and stocky cross-sections leading to an accurate full slenderness range DSM design approach since the resistance reduction due to local buckling and the effect of strain hardening are taken into account, as is the effect of partial yielding of the cross-section in bending. A new method based on the actual stress distribution of the cross-section is also presented for combined loading conditions, where the cross-sectional behaviour is directly tackled through the same strength curve, providing more accurate results than the methods considering the uncoupled problem. Finally, a statistical analysis is presented to demonstrate the reliability of the proposed DSM approach.

\section{HIGHLIGHTS}

- A full slenderness DSM approach is proposed for stainless steel cross-sections.

- The approach considers strain hardening and local buckling effects in different loading conditions.

- A new method is proposed for combined loading considering the actual stress distribution.

- The new approach provides more accurate results than traditional design methods.

- The reliability of the approach is statistically demonstrated. 


\section{KEYWORDS}

Combined actions; cross-sectional resistance; Direct Strength Method; enhanced material properties; stainless steel hollow sections

\section{INTRODUCTION}

Slender stainless steel structures are commonly used in construction as cold-formed elements, exhibiting slender cross-sections that are subjected to local and distortional buckling modes. The effective width method is traditionally used to account for the effects of local and distortional buckling in stainless steel standards (e.g. EN1993-1-4 [1], AS/NZS4673 [2], SEI/ASCE 8-02 [3]) leading to tedious and potentially iterative calculations. In contrast, the Direct Strength Method (DSM) is an alternative non-iterative design method developed by Schafer and Pekoz [4] and implemented in the North American Specification AISI-S100-12 [5] for carbon steel structures. The DSM allows the consideration of all instabilities in a consistent manner through the use of strength curves in conjunction with software to determine the elastic buckling modes. All stainless steel grades present a nonlinear stress-strain relationship with pronounced gradual yielding (strain hardening) that makes them different from carbon steel in designing for stability and strength. Although new strength curves have been proposed to adapt the DSM to stainless steel cross-sections in order to account for the different behaviour exhibited by this material (Becque et al. [6], Niu et al. [7], Huang and Young $[8,9])$, the DSM has not yet been included in stainless steel design standards.

On the other hand, stainless steel standards do not usually take into account the strain hardening effects in the design of stocky cross-sections and overly-conservative capacity predictions are obtained, particularly for austenitic and duplex grades. The Continuous Strength Method (CSM) is a deformation based design method that accounts for the beneficial effect of strain hardening when the resistance of stocky cross-sections is predicted, developed for austenitic and duplex stainless steels by Afshan and Gardner [10] and adapted to ferritics by Bock et al. [11]. Alternatively, Rossi and Rasmussen [12] proposed an alternative design approach that implements strain hardening effects into the DSM formulation, improving the capacity prediction of stocky cross-sections and making it a 
suitable approach for the full cross-sectional slenderness range. However, these expressions were only evaluated for sections in compression.

This paper presents a comprehensive investigation of the cross-sectional behaviour of stainless steel Rectangular and Square Hollow Sections (RHS and SHS) subjected to different loading conditions, including compression, bending and combined compression and bending. A preliminary study on the behaviour of ferritic stainless steel hollow cross-sections subjected to compression, bending and combined uniaxial bending and compression was conducted by the authors in [13]. In the present paper, an extensive experimental database and additional finite element strengths are presented to extend the study to austenitic and duplex stainless steel grades. The DSM-based approach developed by Rasmussen [14] for beam-columns is also modified and adapted to predict the cross-sectional behaviour under combined compression and uniaxial bending loading conditions. The proposed method considers the cross-sectional behaviour directly with a unique strength curve using the local slenderness based on the actual stress distribution instead of considering the uncoupled problem where compression and bending strengths are determined separately.

\section{EXPERIMENTAL DATA AND FE ULTIMATE STRENGTHS}

The analyses and proposals presented in this paper are based on an extensive strength database comprising both experimental and numerical results for different stainless steel grades and loading conditions. This section first presents the collated experimental database and then the relevant information regarding the FE model validation and parametric studies.

\subsection{Collected experimental data}

Previous research works on stainless steel tubular sections have widely investigated the cross-sectional compression, flexural and combined loading capacities from stub column tests, three and four-point bending tests and stub column tests subjected to combined compression and bending moment conditions, respectively. An extensive experimental database with close to 300 experimental results has been collected through an exhaustive literature review, where tests on RHS and SHS from various stainless steel grades subjected to different loading conditions have been gathered. Table 1 summarizes the available stub column tests, while Table 2 presents the experimental data on tubular 
stainless steel beams and Table 3 gathers the different tests performed under combined loading conditions.

Table 1. Summary of stub column tests in compression.

\begin{tabular}{cccc}
\hline Stainless steel & Material grades & References & No. of tests \\
\hline Austenitic & $\begin{array}{c}1.4301,1.4306, \\
1.4318\end{array}$ & {$[16-22]$} & 65 \\
\hline Ferritic & $1.4003,1.4509$ & {$[23-26]$} & 26 \\
\hline $\begin{array}{c}\text { Duplex and } \\
\text { lean duplex }\end{array}$ & $1.4462,1.4162$ & {$[19,22,27-30]$} & 32 \\
\hline
\end{tabular}

Table 2. Summary of beam tests.

\begin{tabular}{cccc}
\hline Stainless steel & Material grades & References & No. of tests \\
\hline Austenitic & $\begin{array}{c}1.4301,1.4318, \\
1.4306\end{array}$ & {$[15,21,25,31-35]$} & 47 \\
\hline Ferritic & $1.4003,1.4509$ & {$[23,25,26,36]$} & 31 \\
\hline $\begin{array}{c}\text { Duplex and } \\
\text { lean duplex }\end{array}$ & $1.4462,1.4162$ & {$[8,22,33,37]$} & 23 \\
\hline
\end{tabular}

Table 3. Summary of stub column tests in combined loading.

\begin{tabular}{cccc}
\hline Stainless steel & Material grades & References & No. of tests \\
\hline Austenitic & $\begin{array}{c}1.4301,1.4571, \\
1.4307,1.4404\end{array}$ & {$[15,22]$} & 21 \\
\hline Ferritic & $1.4003,1.4509$ & {$[24,26]$} & 34 \\
\hline $\begin{array}{c}\text { Duplex and } \\
\text { lean duplex }\end{array}$ & 1.4162 & {$[22]$} & 4 \\
\hline
\end{tabular}

\subsection{FE model validation and parametric studies}

In addition to the available experimental database, parametric studies based on finite element (FE) modelling have been performed in order to augment the range of cross-section slenderness values investigated experimentally. The FE analyses procured a comprehensive database of ultimate strengths covering the full range of cross-sectional slenderness values by testing virtual specimens with crosssections not covered by the existing experimental programmes, including slender cross-sections subjected to local buckling. This section presents the validation of the FE models for ferritic stainless steel RHS and SHS subjected to compression, bending and combined axial compression and bending based on the experimental results reported by Arrayago and Real $[24,36]$. The section also summarizes the conducted parametric studies. 


\subsubsection{General assumptions and model validation}

All FE models were performed by the general purpose software Abaqus. The mid-surface of the crosssection was modelled by the four-node shell element with reduced integration S4R, widely used for cold-formed stainless steel elements. Considering that initial imperfections have an important influence on thin-walled structures, geometric imperfections in the shape of the first elastic buckling mode shape were introduced in all FE models. However, overall imperfections are not relevant for stub columns and beams since cross-section failure is expected, and therefore, only local imperfections with the measured amplitude have been considered in the models. The nonlinear behaviour of stainless steel cross-sections was finally investigated by conducting modified Riks analyses.

For the models representing stub columns subjected to compression and combined loading conditions, the edge elements at the ends of the specimens were kinematically coupled and connected to two reference points where the relevant degrees of freedom were defined. For stub columns subjected to compression all six degrees of freedom were fixed at the lower reference point while only longitudinal displacement was set free at the upper one. For the stub columns subjected to combined loading the rotation around the relevant axis was set free. Loads were introduced as imposed displacements or rotations at the upper reference points in all models. During four-point bending tests, support and loading points were stiffened to prevent web crippling effects, and this stiffening was reproduced with kinematic coupling interaction in the conducted FE models. In these models the bottom faces of the regions corresponding to the support and loading points were coupled and connected to reference points, where boundary conditions and imposed displacements were defined.

Two different material definitions were considered during the validation of the FE models. First, different material definitions based on measured stress-strain properties were assigned to the flat and corner regions of the cross-sections, extending the corner material definition to the adjacent flat parts by a length equal to two times the thickness of the element, as proposed by Theofanous and Gardner [29]. Secondly, weighted average material properties were considered in the FE models, where the same properties were assigned to the entire cross-section as suggested by Hradil and Talja [38], thus allowing the accuracy of this simplification for further FE analyses to be evaluated. The material 
parameters describing the behaviour of flat parts, corner parts and weighted average behaviour can be found in the original publications by Arrayago and Real [24,36].

Table 4 presents the mean values and coefficients of variation (COV) of the numerical-toexperimental ultimate load and deflection ratios (end-shortenings for compression tests $\delta_{\mathrm{u}, \mathrm{FE}} / \delta_{\mathrm{u}, \mathrm{exp}}$, midspan deflections for bending tests $\mathrm{d}_{\mathrm{u}, \mathrm{FE}} / \mathrm{d}_{\mathrm{u}, \exp }$ and end rotations for combined loading tests $\left.\theta_{\mathrm{u}, \mathrm{FE}} / \theta_{\mathrm{u}, \mathrm{exp}}\right)$ for the different loading cases analysed. Results corresponding to the two material definitions considered in the FE model validation have been included in Table 4, those corresponding to the measured properties of the flat and corner regions and to the weighted average material properties for the entire cross-section. The results demonstrate that although the most accurate results (smallest COVs) are obtained when the measured stress-strain curves are considered, the adoption of the simplified weighted average material properties still provides excellent results for stainless steel RHS and SHS under different loading conditions.

Table 4. Comparison of experimental and FE results.

\begin{tabular}{cccccc}
\hline & & \multicolumn{2}{c}{ Flat and corner material } & \multicolumn{2}{c}{ Weighted average material } \\
\cline { 3 - 6 } Test type & & & $\delta_{\mathrm{u}, \mathrm{FE}} / \delta_{\mathrm{u}, \text { exp }}$, & & $\delta_{\mathrm{u}, \mathrm{FE}} / \delta_{\mathrm{u}, \text { exp }}$, \\
& & $\mathrm{F}_{\mathrm{u}, \mathrm{FE}} / \mathrm{F}_{\mathrm{u}, \text { exp }}$ & $\mathrm{d}_{\mathrm{u}, \mathrm{FE}} / \mathrm{d}_{\mathrm{u} \text { exp }}$ & $\mathrm{F}_{\mathrm{u}, \mathrm{FE}} / \mathrm{F}_{\mathrm{u}, \mathrm{exp}}$ & $\mathrm{d}_{\mathrm{u}, \mathrm{FE}} / \mathrm{d}_{\mathrm{u}, \mathrm{exp}}$ \\
& & & $\theta_{\mathrm{u}, \mathrm{FE}} / \theta_{\mathrm{u}, \text { exp }}$ & & $\theta_{\mathrm{u}, \mathrm{FE}} / \theta_{\mathrm{u}, \mathrm{exp}}$ \\
\hline Stub columns under & Mean & 0.99 & 0.88 & 0.95 & 0.88 \\
compression & $\mathrm{COV}$ & 0.012 & 0.072 & 0.040 & 0.125 \\
\hline Beams under four- & Mean & 0.99 & 1.03 & 0.93 & 0.95 \\
point bending & COV & 0.038 & 0.104 & 0.032 & 0.157 \\
\hline Stub columns under & Mean & 1.00 & 0.98 & 0.98 & 0.92 \\
combined loading & COV & 0.019 & 0.053 & 0.022 & 0.089 \\
\hline
\end{tabular}

Experimental curves have been compared to the corresponding FE results considering measured material properties (referred to as $\mathrm{FE}$ ) and the weighted average material properties (FE,average material) and are presented in Figure 1 for a typical stub column and a typical four-point bending test. It is appreciated that in addition to providing excellent ultimate load predictions, the conducted FE models accurately capture the stiffness and the general shape of the response of the specimens. The obtained local buckling failure modes are also found to be in good agreement with those observed in the tests. 


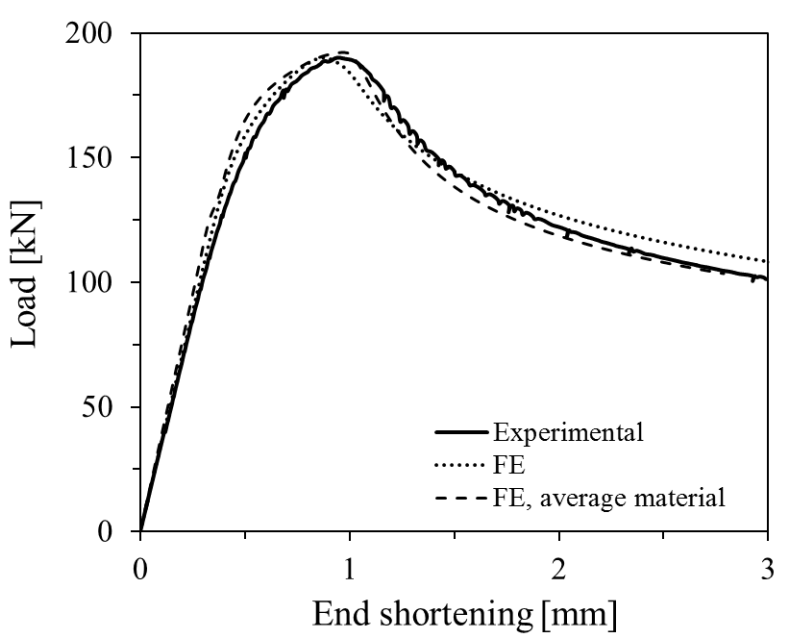

a) Stub column in compression

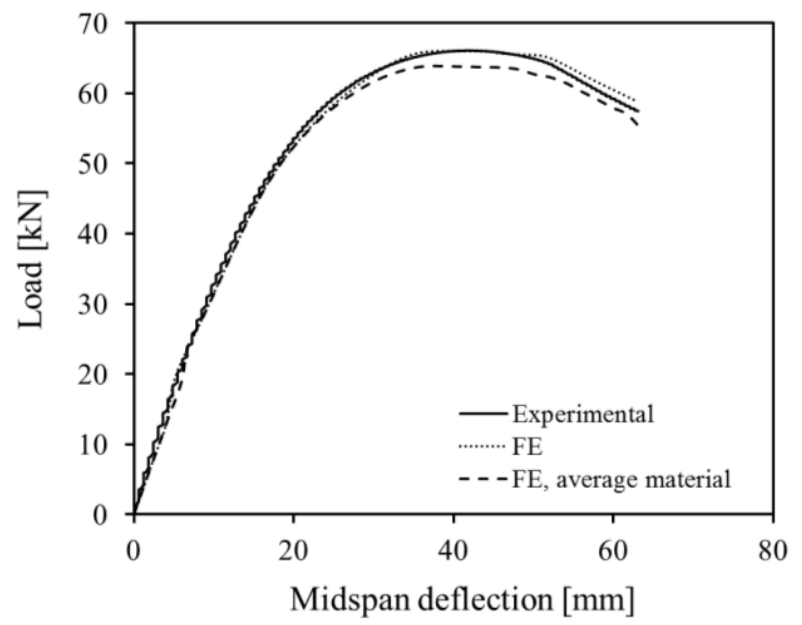

b) Beam under four-point bending test

Figure 1. Comparison between experimental and FE models for compression and bending.

\subsubsection{Parametric studies}

The parametric analyses were developed using a combination of Phyton and Abaqus tools, modelling a variety of RHS and SHS and covering a wide range of cross-sectional slenderness values representing compression, bending and combined loading conditions. The total length of stub columns subjected to compression and combined loading was set equal to three times the widest outer dimension, while all specimens modelled under four-point bending conditions presented a span length of $1500 \mathrm{~mm}$ and a total length of $1700 \mathrm{~mm}$. The outer heights $\mathrm{H}$ and widths B of the considered RHS and SHS ranged from $50 \mathrm{~mm}$ to $150 \mathrm{~mm}$, having aspect ratios $\mathrm{H} / \mathrm{B}$ equal to $1.2,1.5$ and 2 for the modelled RHS. The adopted thicknesses ranged between $2 \mathrm{~mm}$ and $6 \mathrm{~mm}$ to guarantee that both stocky and slender cross-sections were analysed. For combined loading FE models, the nominal load eccentricity $\mathrm{e}_{0}$ was defined as a function of the outer width $\mathrm{B}$, considering $\mathrm{e}_{0} / \mathrm{B}$ ratios equal to $0.25,0.5$ and 1.5. For pure compression 30 stub columns were analysed for each considered stainless steel grade, while 80 four-point bending tests were modelled. Regarding combined loading behaviour, more than 350 stub columns subjected to uniaxial bending plus compression conditions were modelled considering different compression-to-bending loading ratios.

The weighted average material properties were assigned to the entire cross-section as suggested by [38]. The properties were obtained from the results reported in Arrayago and Real [36] for ferritics, 
while those used in the parametric studies by Zhao et al. [39] were considered for austenitic and duplex stainless steels. The most relevant material parameters are presented in Table 5 where $\mathrm{E}$ is the Young's modulus, $\sigma_{0.2}$ is the proof stress corresponding to $0.2 \%$ plastic strain, $\sigma_{\mathrm{u}}$ is the tensile strength and $\varepsilon_{\mathrm{u}}$ is the corresponding ultimate strain. Strain hardening exponents $n$ and $m$ are also provided. The stress-strain curves used for the numerical analyses were obtained using the stress-strain curve formulation presented in [40] in combination with the parameters shown in Table 5.

Table 5. Material parameter definition for parametric studies.

\begin{tabular}{ccccccc}
\hline Stainless steel & $\begin{array}{c}\mathrm{E} \\
{[\mathrm{GPa}]}\end{array}$ & $\begin{array}{c}\sigma_{0.2} \\
{[\mathrm{MPa}]}\end{array}$ & $\begin{array}{c}\sigma_{\mathrm{u}} \\
{[\mathrm{MPa}]}\end{array}$ & $\begin{array}{c}\varepsilon_{\mathrm{u}} \\
{[\%]}\end{array}$ & $\mathrm{n}$ & $\mathrm{m}$ \\
\hline Austenitic & 197.8 & 417 & 651 & 35.9 & 5.5 & 3.7 \\
Ferritic & 185.7 & 490 & 533 & 4.8 & 11.0 & 3.2 \\
Duplex & 201.3 & 707 & 874 & 19.1 & 5.6 & 4.9 \\
\hline
\end{tabular}

Local initial imperfections were introduced in the models by adopting an imperfection pattern in the form of the lowest buckling mode shape obtained by conducting an elastic eigenvalue buckling analysis prior to the ultimate strength nonlinear analysis. The imperfection amplitudes were predicted using the modified Dawson and Walker model [41] proposed by Gardner and Nethercot [42].

\section{DIRECT STRENGTH METHOD FOR CROSS-SECTIONAL RESISTANCE}

This section presents a summary of the existing Direct Strength Method design expressions regarding cross-sectional resistance of carbon and stainless steel structures, together with the most relevant modifications proposed by several authors. Since the experimental and numerical ultimate loads of stainless steel SHS and RHS will be compared to strength predictions for both carbon steel and stainless steel structures, the strength curves for carbon steel structures are also included.

\subsection{Local buckling interaction}

The Direct Strength Method (DSM) considers the effect of local buckling by reducing the resistance of the gross section through a simple strength curve without calculating any effective property of the cross-section. According to AISI-S100-12 [5], the general nominal resistance of a carbon steel crosssection $R_{n l}$ is obtained by reducing the yield load $R_{y}$ due to the effect of local buckling, as given in Eq. (1). When $R_{n l}$ represents the cross-sectional compression resistance $R_{n l}=P_{n l}$ and $R_{y}=P_{y}$ are considered, and for evaluating the bending moment resistance $\mathrm{R}_{\mathrm{n}}=\mathrm{M}_{\mathrm{nl}}$ and $\mathrm{R}_{\mathrm{y}}=\mathrm{M}_{\mathrm{y}}$ are adopted, where 
$\mathrm{P}_{\mathrm{y}}$ is the cross-sectional squash load and $\mathrm{M}_{\mathrm{y}}$ is the first yield bending moment. The reduction due to local buckling interaction depends on the slenderness of the cross-section $\lambda_{1}$ calculated from Eq. (2) which measures the susceptibility of the cross-section to local buckling through the corresponding critical elastic local buckling load $\mathrm{R}_{\mathrm{crl}}$. $\mathrm{R}_{\mathrm{crl}}$ corresponds to the critical elastic local buckling load $\mathrm{P}_{\text {crl }}$ for compression and the critical elastic local buckling moment $\mathrm{M}_{\mathrm{crl}}$ for bending, and can be obtained from a number of numerical methods and related software programs based on finite element and finite strip methods.

$$
\begin{gathered}
\frac{\mathrm{R}_{\mathrm{n} 1}}{\mathrm{R}_{\mathrm{y}}}=\left\{\begin{array}{c}
1 \text { for } \lambda_{1} \leq 0.776 \\
\frac{1}{\lambda_{1}^{0.8}}-\frac{0.15}{\lambda_{1}^{1.6}} \text { for } \lambda_{1}>0.776
\end{array}\right. \\
\lambda_{1}=\sqrt{\frac{\mathrm{R}_{\mathrm{y}}}{\mathrm{R}_{\mathrm{crl}}}}
\end{gathered}
$$

The local buckling strength of stainless steel sections was investigated by Becque et al. [6] through an experimental programme comprising lipped channel sections, I-sections and RHS columns. Since no appreciable differences were found among the different stainless steel grades, a single strength curve was proposed for all alloy families, given by Eq. (3), which is slightly lower than the strength curve provided for carbon steel cross-sections (Eq. (1)) and presents a lower limiting slenderness of 0.474 . Niu et al. [7] demonstrated that the reduction of the bending moment capacity due to local buckling of stainless steel cross-sections can be also conservatively calculated from Eq. (3). Therefore, the local buckling behaviour of stainless steel cross-sections can be derived from the same strength curve regardless of the considered loading case as for carbon steel sections.

$$
\frac{\mathrm{R}_{\mathrm{n} 1}}{\mathrm{R}_{\mathrm{y}}}=\left\{\begin{array}{c}
1 \text { for } \quad \lambda_{1} \leq 0.474 \\
\frac{0.95}{\lambda_{1}^{0.8}}-\frac{0.22}{\lambda_{1}^{1.6}} \text { for } \lambda_{1}>0.474
\end{array}\right.
$$

In recent years, research efforts have focused on the improvement of the DSM approach to extend the method to different materials such as stainless steel and to the low slenderness range in order to provide more accurate capacity predictions over the full range of slenderness values. The incorporation of enhanced material properties and flexural inelastic reserve strength into the DSM approach are particularly relevant when stainless steel cross-sections are analysed. The important strain hardening exhibited by stainless steel grades and the stocky character of some of the 
manufactured RHS and SHS make the original DSM provisions considerably conservative since the compression resistance is limited to the squash load and the ultimate bending moment to the first yield elastic bending moment capacity.

\subsection{Inelastic reserve strength in bending}

Stocky RHS and SHS beams have significant inelastic reserve strength, with ultimate bending moments reaching the full plastic moment capacity $\mathrm{M}_{\mathrm{p}}$, which is usually incorporated in several design standards. EN1993-1-4 [1] assigns full plastic capacity to cross-sections classified as Class 1 or 2 while AS/NZS4673 [2] and SEI/ASCE 8-02 [3] allow the consideration of the inelastic reserve strength by assuming an ideally elastic-plastic stress-strain curve throughout the cross-section, as described in "Procedure II" of the standards, and adopting a compression strain factor $\mathrm{C}_{\mathrm{y}}$ to determine the maximum compressive strain. AS/NZS4673 [2] also contains provisions for utilizing the full plastic capacity for rectangular and square hollow sections.

Shifferaw and Schafer [43] proposed a different design approach for calculating the inelastic reserve strength of cold-formed carbon steel C- and Z-section beams, which was subsequently implemented into the DSM formulation. The approach takes advantage of the inelastic reserve strength for members sufficiently locally stable to develop partial yielding of the cross-section, thus exceeding the elastic bending moment capacity. The approach has been included in the revised AISI-S100-16 [44] Specification. According to [43], the inelastic reserve capacity is assumed to be a function of the maximum compressive strain, represented in Eq. (4) by the compression strain factor $\mathrm{C}_{\mathrm{y}}$ as defined in Eq. (5). The proposed expression for the strain factor is different from that codified in "Procedure II" of AS/NZS4673 [2] and SEI/ASCE 8-02 [3]. In Eq. (5) $\lambda_{\text {ly }}$ is the limiting slenderness for carbon steel cross-sections, equal to 0.776 .

$$
\begin{gathered}
M_{n}=M_{y}+\left(M_{p}-M_{y}\right)\left[1-\frac{1}{C_{y}^{2}}\right] \\
C_{y}=\left(\frac{\lambda_{l y}}{\lambda_{1}}\right)^{0.5}
\end{gathered}
$$


However, in order to be consistent with the scope of AISI-S100-12 [5], Shifferaw and Schafer [43] limited the maximum strain in inelastic bending to $3 \varepsilon_{\mathrm{y}}$ where $\varepsilon_{\mathrm{y}}$ is the yield strain. No specific limit was provided for stainless steel beams but since "Procedure II" in [2] and [3] also limits the $\mathrm{C}_{\mathrm{y}}$ parameter to a maximum value of 3 , the same limit has been considered in the following analysis.

\subsection{Effect of strain hardening}

Rossi and Rasmussen [12] included the effect of the strain hardening into the DSM design approach for stainless steel cross-sections by adopting a linear expression relating the cross- sectional resistance to the slenderness instead of using the classical horizontal yield limit at low slenderness values. The ultimate tensile strength $\sigma_{\mathrm{u}}$ was considered in the definition of the resistance so the ratio between the predicted capacity and the conventional yield limit tends to $\sigma_{\mathrm{u}} / \sigma_{0.2}$ as the slenderness approaches zero, following a linear curve. The predicted cross-sectional resistance $\mathrm{R}_{\text {enh_nl }}$ that considers both strain hardening effects for stocky cross-sections while reducing the resistance due to the local buckling proposed for stainless steel cross-sections is presented in Eq. (6). Although this approach was originally proposed for compression and distortional buckling effects, it can be easily extended to different loading conditions such as bending. A simple modification of this expression to be adapted for the carbon steel strength curve is proposed herein (see Eq. (7)), considering a different limiting slenderness but following the same procedure described in [12].

$$
\begin{aligned}
\frac{\mathrm{R}_{\text {enh_nl }}}{\mathrm{R}_{\mathrm{y}}}=\left\{\begin{aligned}
& 1+\left(1-2.11 \lambda_{1}\right)\left(\frac{\sigma_{\mathrm{u}}}{\sigma_{0.2}}-1\right) \text { for } \lambda_{1} \leq 0.474 \\
& \frac{0.95}{\lambda_{1}^{0.8}}-\frac{0.22}{\lambda_{1}^{1.6}} \text { for } \lambda_{1}>0.474 \text { (Stainless steel sections) }
\end{aligned}\right. \\
\frac{\mathrm{R}_{\mathrm{enh} \_\mathrm{nl}}}{\mathrm{R}_{\mathrm{y}}}=\left\{\begin{aligned}
1+\left(1-1.29 \lambda_{1}\right)\left(\frac{\sigma_{\mathrm{u}}}{\sigma_{0.2}}-1\right) \text { for } \lambda_{1} \leq 0.776 \\
\frac{1}{\lambda_{1}^{0.8}}-\frac{0.15}{\lambda_{1}^{1.6}} \text { for } \lambda_{1}>0.776
\end{aligned} \quad\right. \text { (Carbon steel sections) }
\end{aligned}
$$

\subsection{Adaptation of the DSM method for beam-columns to cross-sections}

AISI-S100-12 [5] does not provide a specific expression based on the DSM for the design of beamcolumns so the general linear interaction equation is applicable with the compression and bending resistances calculated separately from the DSM provisions. However, Rasmussen [14] extended the 
DSM approach for compression members to beam-columns by introducing a member resistance parameter $r_{n e}$ equal to the radial distance in the $\mathrm{M} / \mathrm{M}_{\mathrm{y}}-\mathrm{P} / \mathrm{P}_{\mathrm{y}}$ plane. In this approach, the beam-column behaviour is directly calculated with a unique strength curve considering the member and section slenderness based on the elastic instabilities of the member subjected to the actual stress distribution. The approach can be adapted to predict the capacity of cross-sections subjected to combined loading conditions. The basis of the approach is the same since the different resistance parameters are calculated as radial distances in the $\mathrm{M} / \mathrm{M}_{\mathrm{y}}-\mathrm{P} / \mathrm{P}_{\mathrm{y}}$ plane (see Figure 2). The most notable modification is that the radial distance governing the member behaviour changes to the yielding radial distance $r_{y}$ calculated from Eq. (8) when cross-sections subjected to combined loading are considered, see point A in Figure 2. In the Figure, $\mathrm{P}_{\mathrm{oy}}$ and $\mathrm{M}_{\mathrm{oy}}$ represent the axial load and bending moment that cause yielding of the cross-section, respectively, and can be obtained from an interaction expression similar to that given in Eq. (9) assuming that $\mathrm{M}_{\mathrm{oy}}=\mathrm{e} \cdot \mathrm{P}_{\mathrm{oy}}$, where e is the eccentricity of the compression load.
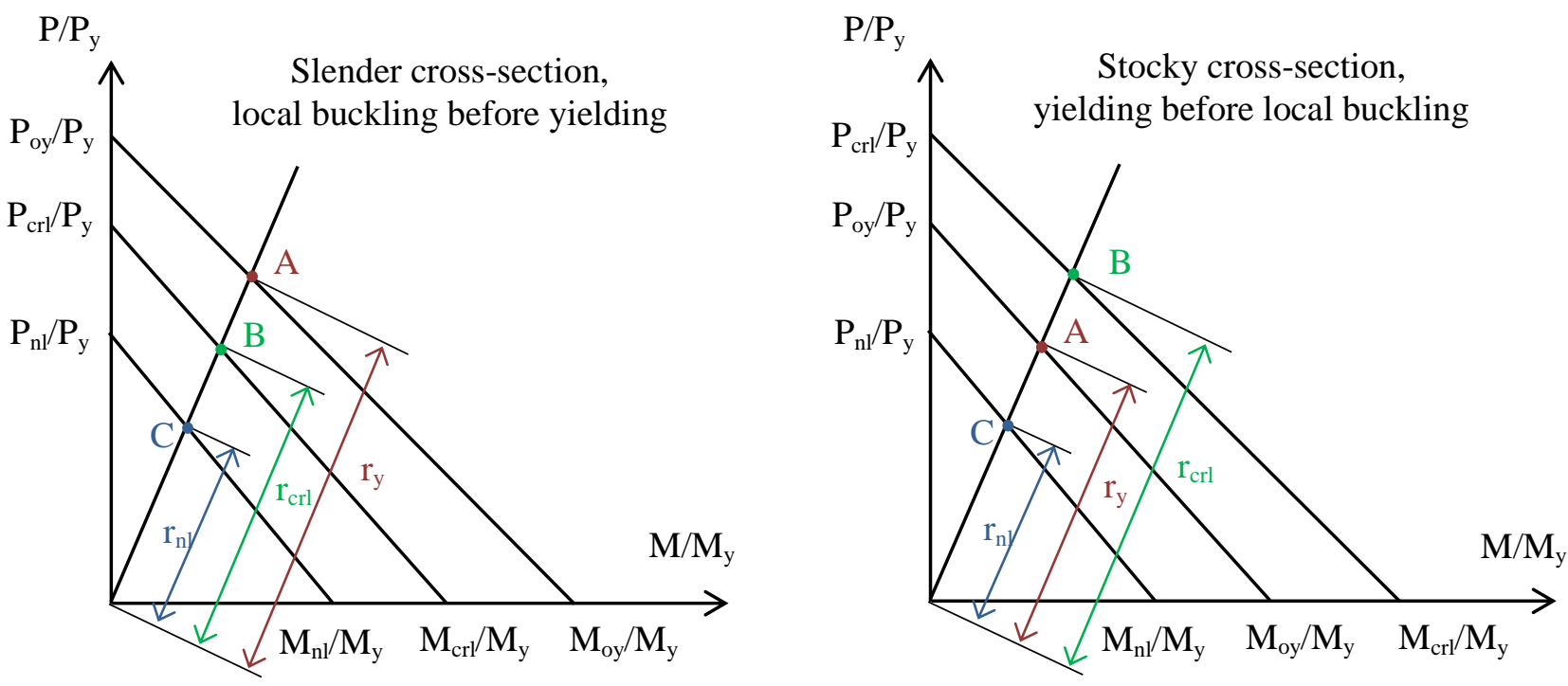

Figure 2. Graphical definition of the extended radial distances for the combined loading approach.

$$
\begin{gathered}
r_{y}=\sqrt{\left(\frac{P_{o y}}{P_{y}}\right)^{2}+\left(\frac{M_{o y}}{M_{y}}\right)^{2}} \\
\frac{P_{o y}}{P_{y}}+\frac{M_{o y}}{M_{y}}=1
\end{gathered}
$$


The local buckling behaviour of the cross-section (point B) is evaluated through the local buckling radial distance $r_{\text {crl }}$ calculated from Eq. (10) and combined with the yielding parameter $r_{y}$ to obtain a generalized slenderness $\lambda_{n}$, as per Eq. (11). In Eq. (10), $P_{\text {ocr }}$ and $M_{\text {ocr }}$ represent the local buckling compression load and bending moment, respectively, and are calculated from an elastic buckling analysis using the actual applied stress distribution.

$$
\begin{gathered}
\mathrm{r}_{\mathrm{crl}}=\sqrt{\left(\frac{\mathrm{P}_{\mathrm{ocr}}}{\mathrm{P}_{\mathrm{y}}}\right)^{2}+\left(\frac{\mathrm{M}_{\mathrm{ocr}}}{\mathrm{M}_{\mathrm{y}}}\right)^{2}} \\
\lambda_{\mathrm{n}}=\sqrt{\frac{\mathrm{r}_{\mathrm{y}}}{\mathrm{r}_{\mathrm{crl}}}}
\end{gathered}
$$

Once the generalized slenderness $\lambda_{n}$ of the cross-section is known, the resistance of the cross-section $\mathrm{r}_{\text {enh_nl }}$ is determined from the strength curves given in Eqs. (12) and (13) for carbon steel and stainless steel sections respectively and the predicted compression and flexural strengths of the cross-section $\mathrm{P}_{\mathrm{nl}}$ and $\mathrm{M}_{\mathrm{nl}}$ can be finally determined from Eq. (14). Note that Eqs. (12) and (13) incorporate the effects of enhanced material properties in the low slenderness range and local buckling.

$$
\begin{aligned}
& \frac{\mathrm{r}_{\mathrm{enh} \_\mathrm{nl}}}{\mathrm{r}_{\mathrm{y}}}=\left\{\begin{array}{c}
1+\left(1-1.29 \lambda_{\mathrm{n}}\right)\left(\frac{\sigma_{\mathrm{u}}}{\sigma_{0.2}}-1\right) \text { for } \lambda_{\mathrm{n}} \leq 0.776 \\
\frac{1}{\lambda_{\mathrm{n}}^{0.8}}-\frac{0.15}{\lambda_{\mathrm{n}}^{1.6}} \text { for } \lambda_{\mathrm{n}}>0.776
\end{array} \quad\right. \text { (Carbon steel sections) } \\
& \frac{\mathrm{r}_{\text {enh_nl }}}{\mathrm{r}_{\mathrm{y}}}=\left\{\begin{array}{c}
1+\left(1-2.11 \lambda_{\mathrm{n}}\right)\left(\frac{\sigma_{\mathrm{u}}}{\sigma_{0.2}}-1\right) \text { for } \lambda_{\mathrm{n}} \leq 0.474 \\
\frac{0.95}{\lambda_{\mathrm{n}}^{0.8}}-\frac{0.22}{\lambda_{\mathrm{n}}^{1.6}} \text { for } \lambda_{\mathrm{n}}>0.474
\end{array} \quad\right. \text { (Stainless steel sections) } \\
& r_{\text {enh }_{n} \mathrm{nl}}=\sqrt{\left(\frac{\mathrm{P}_{\mathrm{n} 1}}{\mathrm{P}_{\mathrm{y}}}\right)^{2}+\left(\frac{\mathrm{M}_{\mathrm{nl}}}{\mathrm{M}_{\mathrm{y}}}\right)^{2}}
\end{aligned}
$$

\section{CROSS-SECTIONS SUBJECTED TO COMPRESSION}

This section presents the assessment of the local buckling strength curves and the applicability of the enhanced material property approach proposed in [12] for stainless steel RHS and SHS subjected to pure compression. Stub column results for austenitic, ferritic, duplex and lean duplex stainless steel RHS and SHS from the tests reported in Table 1 and the FE results obtained from the parametric studies have been considered in the analysis. 
Figure 3 presents the experimental and numerical ultimate loads $\mathrm{P}_{\mathrm{u}}$ normalized by the respective squash loads $\mathrm{P}_{\mathrm{y}}$ and plotted against the corresponding cross-sectional slenderness $\lambda_{1}$ calculated from Eq. (2). All critical elastic local buckling loads $P_{c r l}$ and moments $M_{c r l}$ considered in this paper have been calculated from a buckling analysis conducted with CUFSM (Schafer and Ádány [45]). Strength curves accounting for local buckling effects given for carbon steel and stainless steel cross-sections are depicted in Figure 3 and the enhanced material property approaches for different stainless steel families are also presented, based on the DSM strength curve for carbon steel given in Eq. (7). Each experimental data point presents a different $\sigma_{\mathrm{u}} / \sigma_{0.2}$ ratio and needs to be analysed with that particular value. However, for simplicity, Figure 3 only presents the enhanced property curves for the average $\sigma_{\mathrm{u}} / \sigma_{0.2}$ ratios of the considered experimental results.

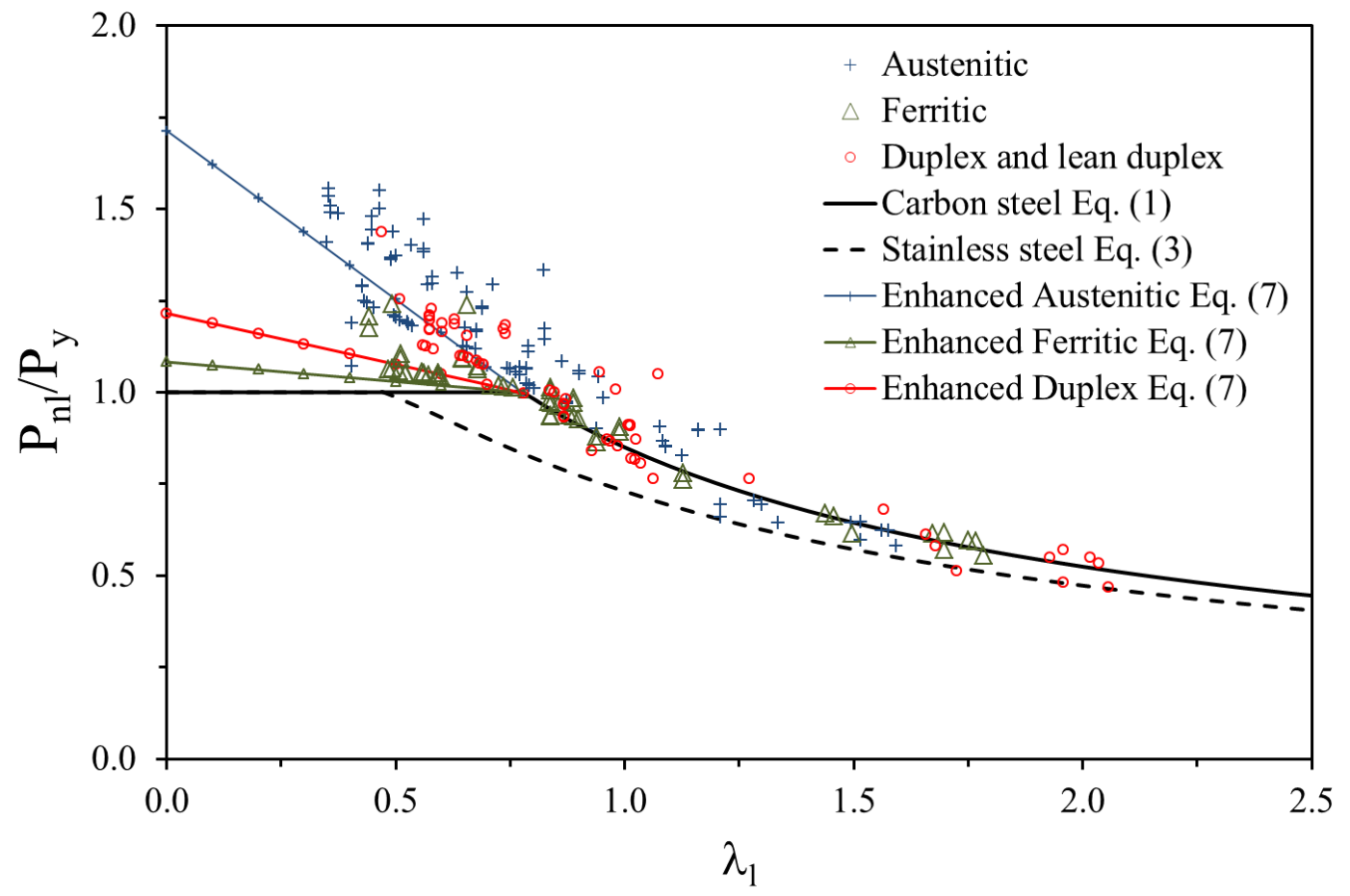

Figure 3. Assessment of DSM approach for stainless steel RHS and SHS in compression.

Figure 3 demonstrates that the local buckling curve codified for carbon steel cross-sections provides a better estimation of the ultimate capacity of slender stainless steel cross-sections in compression and it also shows the improvement introduced when the enhanced material properties are considered for stocky cross-sections. The reason for the unexpected better agreement between the ultimate strengths and the DSM strength curve for carbon steel rather than the DSM strength curve for stainless steel is 
likely related to the fact that the stainless steel DSM strength curve is based on research on open sections with substantially smaller thicknesses than those considered in the present study on closed sections, and hence are likely to have been more detrimentally affected by local geometric imperfections.

Table 6 and Table 7 present the assessment of the different approaches for stainless steel RHS and SHS subjected to compression, where the mean values and COVs of the predicted-to-experimental (or FE) capacity ratios $P_{\text {pred }} / P_{u}$ are reported for the different stainless steel families. Results corresponding to stocky cross-sections are presented in Table 6 for the DSM approach including enhanced material properties $\mathrm{P}_{\mathrm{DSM}}$ and $\mathrm{P}_{\text {pred }} / \mathrm{P}_{\mathrm{u}}$ ratios for the design approaches codified in different standards and the Continuous Strength Method (CSM) have also been included for comparison. $\mathrm{P}_{\mathrm{EN}}, \mathrm{P}_{\mathrm{AS} / \mathrm{SEI}}$ and $\mathrm{P}_{\mathrm{CSM}}$ correspond to the design provisions given in EN1993-1-4 [1], AS/NZS4673 [2]-SEI/ASCE 8-02 [3] and CSM respectively. Results corresponding to the provisions given in different standards are found to be safe but conservative, obtaining marginally better predictions for AS/NZS4673 [2]-SEI/ASCE 802 [3] and for EN1993-1-4 [1]. The conservatism is highest for austenitic stainless steel crosssections, where strain hardening effects are more prevalent, followed by duplex and ferritic grades.

Table 6. Assessment of design approaches for stocky stainless steel cross-sections subjected to compression

\begin{tabular}{ccccccc}
\hline \multirow{2}{*}{ Grade } & & $\begin{array}{c}\mathrm{P}_{\text {DSM }} / \mathrm{P}_{\mathrm{u}} \\
\text { CS-curve }\end{array}$ & $\begin{array}{c}\mathrm{P}_{\mathrm{DSM}} / \mathrm{P}_{\mathrm{u}} \\
\text { SS-curve }\end{array}$ & $\mathrm{P}_{\mathrm{CSM}} / \mathrm{P}_{\mathrm{u}}$ & $\mathrm{P}_{\mathrm{EN}} / \mathrm{P}_{\mathrm{u}}$ & $\mathrm{P}_{\mathrm{AS} / \mathrm{SEI}} / \mathrm{P}_{\mathrm{u}}$ \\
\hline \multirow{2}{*}{ Austenitic } & Mean & 0.88 & 0.76 & 0.80 & 0.76 & 0.77 \\
& COV & 0.119 & 0.072 & 0.082 & 0.106 & 0.122 \\
\hline \multirow{2}{*}{ Ferritic } & Mean & 0.94 & 0.84 & 0.93 & 0.91 & 0.93 \\
& COV & 0.053 & 0.018 & 0.050 & 0.049 & 0.051 \\
\hline \multirow{2}{*}{ Duplex } & Mean & 0.89 & 0.70 & 0.86 & 0.83 & 0.86 \\
& COV & 0.050 & 0.076 & 0.056 & 0.046 & 0.056 \\
\hline \multirow{2}{*}{ All exp. } & Mean & 0.89 & 0.76 & 0.85 & 0.80 & 0.81 \\
& COV & 0.064 & 0.087 & 0.086 & 0.119 & 0.122 \\
\hline \multirow{2}{*}{ All FE } & Mean & 0.97 & 0.84 & 0.91 & 0.86 & 0.90 \\
& COV & 0.019 & 0.004 & 0.044 & 0.052 & 0.056 \\
\hline \multirow{2}{*}{ ALL } & Mean & 0.90 & 0.77 & 0.87 & 0.81 & 0.83 \\
& COV & 0.095 & 0.086 & 0.082 & 0.110 & 0.119 \\
\hline
\end{tabular}

According to the results presented in Figure 3 and Table 6, the best method for the prediction of the compression resistance for stainless steel stocky cross-sections is the DSM approach considering the enhanced material properties based on the carbon steel strength curve given in Eq. (7), although very 
similar and excellent results are obtained for the CSM since both approaches consider strain hardening effects. The improvement in strength predictions is most notable for austenitic stainless steel crosssections.

The accuracy of the DSM strength curves for slender cross-sections is evaluated from the data with local slenderness higher than $\lambda_{1}>0.776$. These results are reported in Table 7 and are compared with those corresponding to current design methods based on the effective width methods codified in standards. The results demonstrate that the DSM strength curve corresponding to carbon steel crosssections given in Eq. (1) is the approach that provides both accurate and safe results for slender stainless steel cross-sections subjected to pure compression. Although the highest $\mathrm{P}_{\text {pred }} / \mathrm{P}_{\mathrm{u}}$ ratios are obtained for AS/NZS4673 [2] and SEI/ASCE 8-02 [3], the capacity of a number of austenitic and duplex specimens is substantially overestimated by more than $20 \%$. However, for ferritic stub columns, the mean $\mathrm{P}_{\text {pred }} / \mathrm{P}_{\mathrm{u}}$ ratio being close to unity and the low scatter (COV) prove the accuracy of the results. This indicates that the reduction function given in [2] and [3] is valid for ferritic stainless steel sections, which are more similar to carbon steel sections than austenitic and duplex alloy sections, but unconservative for the austenitic and duplex grades.

Table 7. Assessment of design approaches for slender stainless steel cross-sections subjected to compression.

\begin{tabular}{cccccc}
\hline \multirow{2}{*}{ Grade } & & $\begin{array}{c}\mathrm{P}_{\text {DSM }} / \mathrm{P}_{\mathrm{u}} \\
\text { CS-curve }\end{array}$ & $\begin{array}{c}\mathrm{P}_{\text {DSM }} / \mathrm{P}_{\mathrm{u}} \\
\text { SS-curve }\end{array}$ & $\mathrm{P}_{\mathrm{EN}} / \mathrm{P}_{\mathrm{u}}$ & $\mathrm{P}_{\mathrm{AS} / \mathrm{SEI}} / \mathrm{P}_{\mathrm{u}}$ \\
\hline \multirow{2}{*}{ Austenitic } & Mean & 0.94 & 0.78 & 0.85 & 0.96 \\
& COV & 0.093 & 0.100 & 0.116 & 0.121 \\
\hline \multirow{2}{*}{ Ferritic } & Mean & 0.99 & 0.86 & 0.91 & 1.02 \\
& COV & 0.033 & 0.054 & 0.056 & 0.072 \\
\hline \multirow{2}{*}{ Duplex } & Mean & 0.98 & 0.83 & 0.90 & 1.02 \\
& COV & 0.080 & 0.082 & 0.102 & 0.117 \\
\hline \multirow{2}{*}{ All exp. } & Mean & 0.95 & 0.79 & 0.84 & 0.95 \\
& COV & 0.081 & 0.085 & 0.079 & 0.076 \\
\hline \multirow{2}{*}{ All FE } & Mean & 1.00 & 0.86 & 0.94 & 1.06 \\
& COV & 0.046 & 0.060 & 0.074 & 0.095 \\
\hline \multirow{2}{*}{ ALL } & Mean & 0.98 & 0.83 & 0.89 & 1.01 \\
& COV & 0.070 & 0.087 & 0.094 & 0.106 \\
\hline
\end{tabular}

\section{CROSS-SECTIONS SUBJECTED TO BENDING}

The lateral-torsional strength of RHS and SHS beams is high and since cross-sectional failure is usually expected, the analysis presented in this paper will only focus on the cross-sectional behaviour 
of stainless steel hollow beams. The first yield capacity is significantly exceeded for beams with stocky cross-sections, so the effects of strain hardening and partial yielding of the cross-section have been incorporated into the analysis. The enhanced material property curves proposed in [12] and the inelastic reserve strength expression with the different definitions of the compression strain factor $\mathrm{C}_{\mathrm{y}}$ have been considered. The local buckling behaviour of stainless steel beams with slender crosssections has also been investigated through the strength curves given by Eq. (1) and Eq. (3) for carbon steel and stainless steel sections, respectively.

The experimental and numerical bending moment capacities of the studied experimental and numerical specimens are presented in Figure 4, normalized by the first yield moment $\mathrm{M}_{\mathrm{y}}$ and plotted against the corresponding local slenderness calculated from Eq. (2). Figure 4 also includes the local buckling curves for carbon and stainless steel cross-sections, and the different curves that consider the enhanced material properties based on the DSM strength curve for carbon steel. Note again that since each experimental result is characterized by a different $\sigma_{\mathrm{u}} / \sigma_{0.2}$ ratio, only the enhanced material property curves corresponding to the average $\sigma_{\mathrm{u}} / \sigma_{0.2}$ ratios are presented. As for the pure compression behaviour analysed in the previous section, Figure 4 suggests that the local buckling strength curve proposed for stainless steel cross-sections underestimates the flexural capacity of the analysed stainless steel RHS and SHS beams and the curve provided for carbon steel cross-sections is more accurate. It is also appreciated that the consideration of the enhanced material properties according to the method proposed in [12] introduces important improvement in the flexural capacity prediction of stocky cross-sections, still showing a considerable conservatism. 


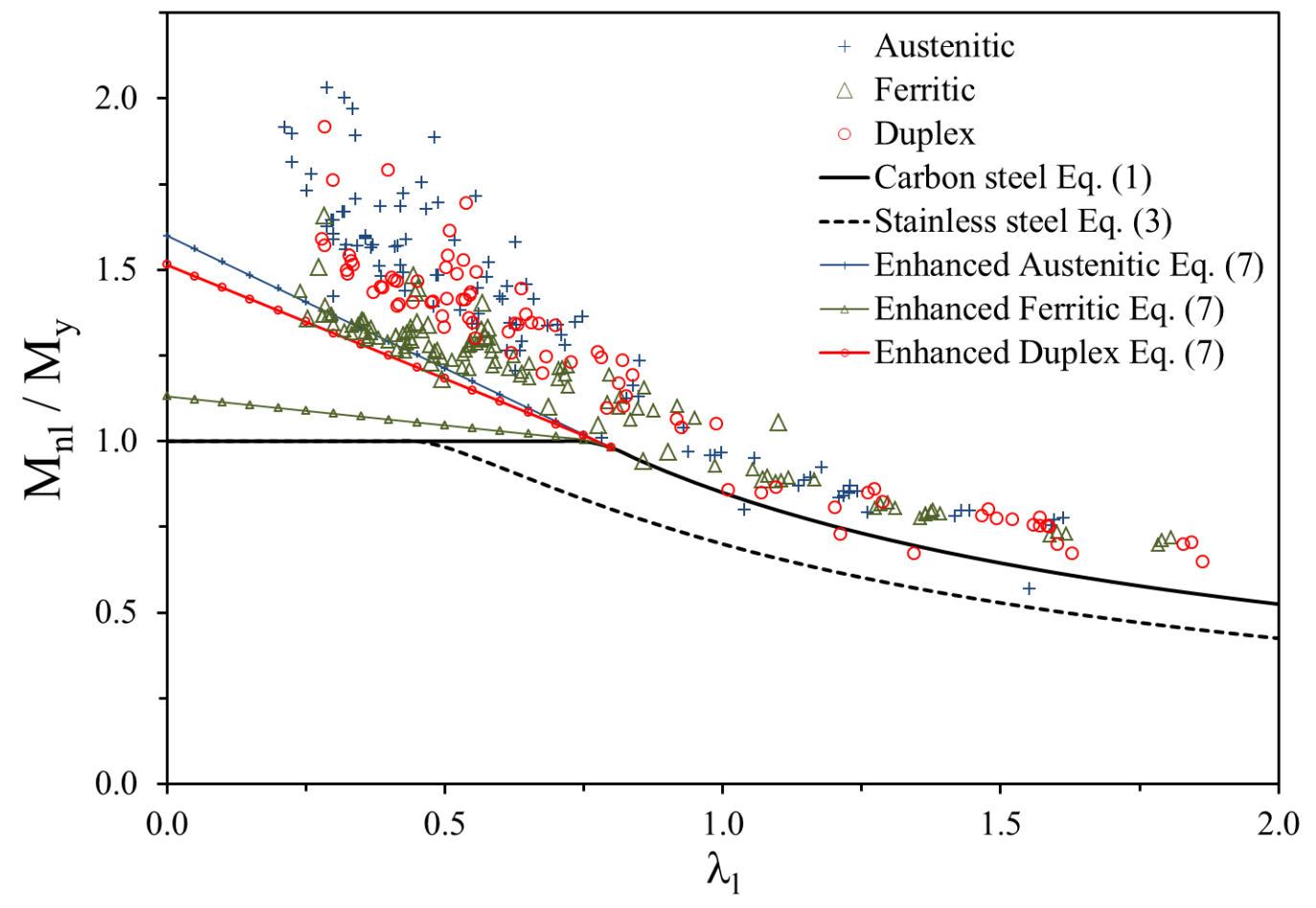

Figure 4. Assessment of DSM approach for stainless steel RHS and SHS beams based on the elastic bending capacity $\mathrm{M}_{\mathrm{y}}$.

To reduce the conservatism, the DSM approach suggested in [43] that considers the inelastic reserve strength $M_{n}$ has been adopted instead of the first yield moment $M_{y}$. Table 8 and Table 9 present the mean values and COVs of the predicted-to-experimental (or FE) bending moment capacity ratios $\mathrm{M}_{\text {pred }} / \mathrm{M}_{\mathrm{u}}$ for stocky and slender cross-sections respectively. Regarding stocky cross-sections, Table 8 compares results obtained from the DSM-based enhanced material property approaches $\mathrm{M}_{\mathrm{DSM}}$ derived from Eq. (6) and Eq. (7) with those obtained for different standards and the CSM. $\mathrm{M}_{\mathrm{EN}}$ represents the bending capacity predicted by EN1993-1-4 [1], while $\mathrm{M}_{\mathrm{AS} / \mathrm{SEI}}$ and $\mathrm{M}_{\mathrm{CSM}}$ correspond to AS/NZS4673 [2]-SEI/ASCE 8-02 [3] and the CSM predictions respectively. Note that while EN1993-1-4 [1] assigns a plastic bending moment capacity $\mathrm{M}_{\mathrm{p}}$ to Class 1 and 2 cross-sections, AS/NZS4673 [2] and SEI/ASCE 8-02 [3] are based on "Procedure II" with an elastic-plastic bending moment distribution and a maximum value of compression strain equal to $3 \varepsilon_{\mathrm{y}}$. AS/NZS4673 [2] also adopts the full plastic capacity for tubular sections but considering that for doubly symmetric cross-sections the $3 \varepsilon_{\mathrm{y}}$ limit provides bending moment predictions very close to $\mathrm{M}_{\mathrm{p}}$, only the strength predictions based on the $3 \varepsilon_{\mathrm{y}}$ limit are used in applying [2] and [3] which therefore produce the same design strengths. 
Table 8. Assessment of design approaches for stocky stainless steel cross-sections subjected to bending.

\begin{tabular}{cccccccc}
\hline \multirow{2}{*}{ Grade } & & $\begin{array}{c}\mathrm{M}_{\text {DSM }} / \mathrm{M}_{\mathrm{u}} \\
\text { CS-curve }\end{array}$ & $\begin{array}{c}\mathrm{M}_{\text {DSM }} / \mathrm{M}_{\mathrm{u}} \\
\text { CS-curve } \\
\text { Proc. II C }\end{array}$ & $\begin{array}{c}\mathrm{M}_{\mathrm{DSM}} / \mathrm{M}_{\mathrm{u}} \\
\text { SS-curve }\end{array}$ & $\mathrm{M}_{\mathrm{CSM}} / \mathrm{M}_{\mathrm{u}}$ & $\mathrm{M}_{\mathrm{EN}} / \mathrm{M}_{\mathrm{u}}$ & $\mathrm{M}_{\mathrm{AS} / \mathrm{SEI}} / \mathrm{M}_{\mathrm{u}}$ \\
\cline { 3 - 8 } & & $(1)$ & $(2)$ & $(3)$ & $(4)$ & $(5)$ & $(6)$ \\
\hline \multirow{2}{*}{ Austenitic } & Mean & 0.80 & 0.96 & 0.74 & 0.85 & 0.74 & 0.77 \\
& COV & 0.097 & 0.075 & 0.085 & 0.097 & 0.093 & 0.097 \\
\hline \multirow{2}{*}{ Ferritic } & Mean & 0.89 & 0.96 & 0.88 & 0.94 & 0.87 & 0.93 \\
& COV & 0.064 & 0.042 & 0.059 & 0.072 & 0.096 & 0.041 \\
\hline \multirow{2}{*}{ Duplex } & Mean & 0.78 & 0.91 & 0.77 & 0.88 & 0.77 & 0.84 \\
& COV & 0.045 & 0.067 & 0.052 & 0.085 & 0.105 & 0.067 \\
\hline \multirow{2}{*}{ All exp. } & Mean & 0.82 & 0.91 & 0.76 & 0.83 & 0.73 & 0.80 \\
& COV & 0.085 & 0.084 & 0.099 & 0.090 & 0.120 & 0.123 \\
\hline \multirow{2}{*}{ All FE } & Mean & 0.84 & 0.97 & 0.82 & 0.93 & 0.84 & 0.88 \\
& COV & 0.097 & 0.033 & 0.098 & 0.064 & 0.098 & 0.074 \\
\hline \multirow{2}{*}{ ALL } & Mean & 0.83 & 0.95 & 0.80 & 0.89 & 0.80 & 0.85 \\
& COV & 0.094 & 0.065 & 0.104 & 0.096 & 0.122 & 0.104 \\
\hline
\end{tabular}

Comparing DSM results that consider enhanced material properties given in Columns (1) and (3) of Table 8 with those obtained according to "Procedure II" in [2] and [3] and presented in Column (6) $\left(\mathrm{M}_{\mathrm{AS} / \mathrm{SEI}} / \mathrm{M}_{\mathrm{u}}\right)$, it can be observed that higher $\mathrm{M}_{\text {pred }} / \mathrm{M}_{\mathrm{u}}$ ratios are generally obtained for the latter even if this approach does not account for strain hardening effects. This suggests that the definition of the compression strain factor $\mathrm{C}_{\mathrm{y}}$ proposed in [43] for cold-formed carbon steel beams is too conservative for stainless steel RHS and SHS. Hence, results based on the $\mathrm{C}_{\mathrm{y}}$ definition provided in "Procedure II" and given in Eq. (15) have also been included in Table 8. Although all approaches provide reasonable predictions for the bending moment capacity of stainless steel RHS and SHS, according to these results the best approach is the DSM approach including the enhanced material properties based on the carbon steel strength curve given in Eq. (7) and the $\mathrm{C}_{\mathrm{y}}$ definition provided in [2] and [3], Eq. (15).

$$
\mathrm{C}_{\mathrm{y}}=\left\{\begin{array}{cc}
\lambda_{1} & \leq 0.58 \\
3-2\left(\frac{\lambda_{1}^{3}-0.58}{0.196}\right) & 0.58 \leq \lambda_{1} \leq 0.776 \\
\lambda_{1} & \geq 0.776
\end{array}\right.
$$

With respect to current codified expressions (Columns (5) and (6) of Table 8), the pronounced conservatism observed for austenitic and duplex stainless steel RHS and SHS cross-sections in bending can be attributed to the fact that strain hardening effects are not accounted when the predicted strengths are calculated according to the different standards. The best results are obtained for the 
"Procedure II" approach in AS/NZS4673 [2] and SEI/ASCE 8-02 [3] since the consideration of the inelastic strength reserve is allowed, while for the cross-sections classified as Class 3 in EN1993-1-4 [1] only elastic bending capacities are assigned.

Figure 5 shows the experimental and numerical bending moment capacities normalized by the flexural resistance considering the inelastic reserve strength $M_{n}$ calculated from Eq. (4) considering the compression strain factor $\mathrm{C}_{\mathrm{y}}$ given in Eq. (15). Figure 5 clearly shows the improvement of the new formulation, reducing considerably the underestimation and scatter of the predicted ultimate bending moment capacities for all stainless steel grades.

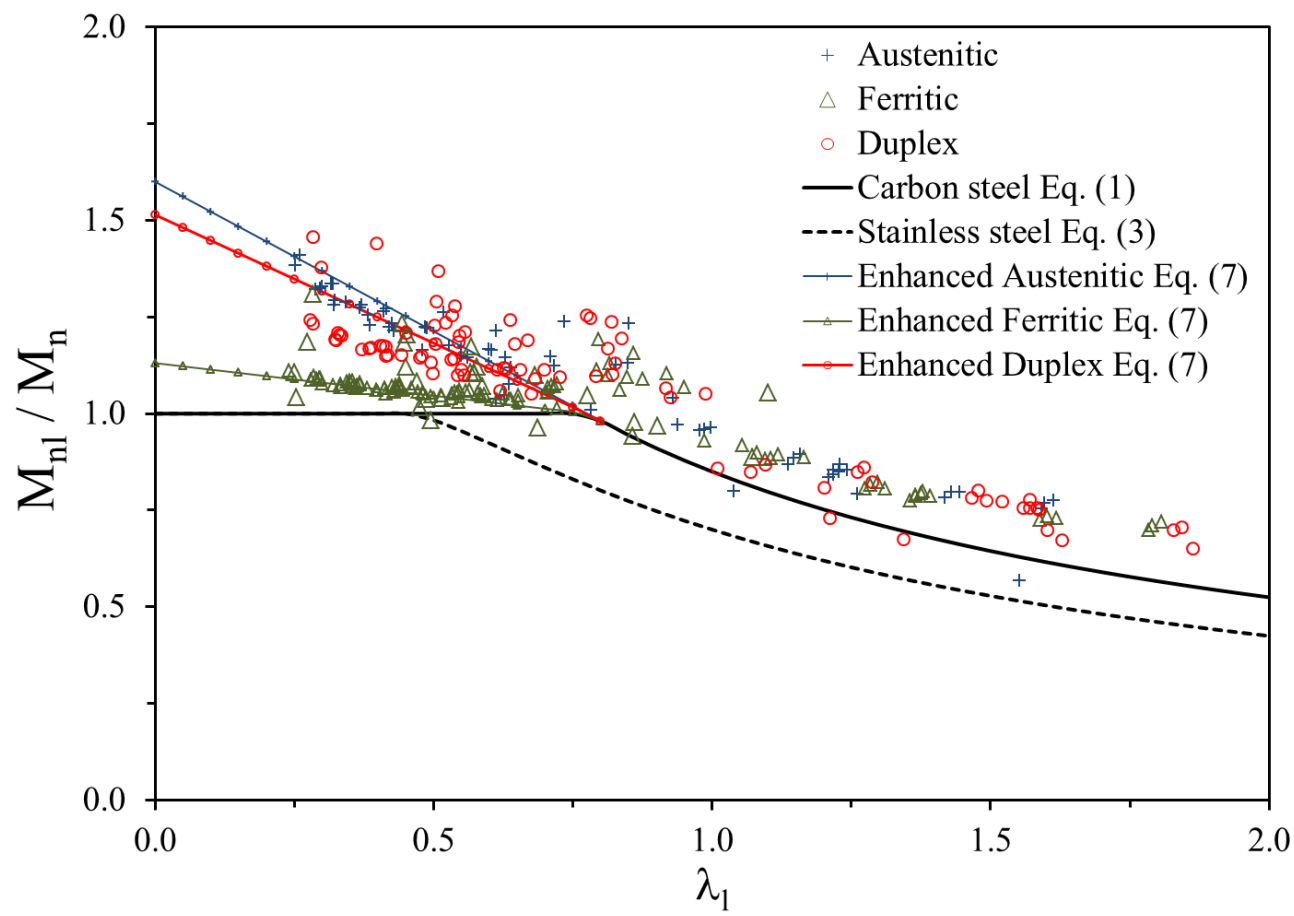

Figure 5. Assessment of DSM approach for stainless steel RHS and SHS beams based on the inelastic reserve strength capacity $M_{n}$.

The assessment of the different approaches for slender cross-sections in bending is presented in Table 9. The mean $\mathrm{M}_{\text {pred }} / \mathrm{M}_{\mathrm{u}}$ ratios closest to unity $\left(\mathrm{M}_{\mathrm{EN}} / \mathrm{M}_{\mathrm{u}}\right.$ and $\left.\mathrm{M}_{\mathrm{AS} / \mathrm{SEI}} / \mathrm{M}_{\mathrm{u}}\right)$ are obtained for the effective width methods given in standards [1-3], although over-predictions lead to highly scattered predictions. Alternatively, the DSM predictions based on the carbon steel strength curve given in Eq. (1) are accurate, albeit about $15 \%$ conservative on average, and less scattered, thus presenting an excellent alternative to the effective width method for stainless steel hollow sections in bending. 
Table 9. Assessment of design approaches for slender stainless steel cross-sections subjected to bending.

\begin{tabular}{cccccc}
\hline \multirow{2}{*}{ Grade } & & $\begin{array}{c}\mathrm{M}_{\mathrm{DSM}} / \mathrm{M}_{\mathrm{u}} \\
\text { CS-curve }\end{array}$ & $\begin{array}{c}\mathrm{M}_{\mathrm{DSM}} / \mathrm{M}_{\mathrm{u}} \\
\mathrm{SS}-\text {-curve }\end{array}$ & $\mathrm{M}_{\mathrm{EN}} / \mathrm{M}_{\mathrm{u}}$ & $\mathrm{M}_{\mathrm{AS} / \mathrm{SEI}} / \mathrm{M}_{\mathrm{u}}$ \\
\hline \multirow{2}{*}{ Austenitic } & Mean & 0.88 & 0.71 & 0.92 & 0.89 \\
& COV & 0.079 & 0.106 & 0.080 & 0.147 \\
\hline \multirow{2}{*}{ Ferritic } & Mean & 0.87 & 0.75 & 0.92 & 0.93 \\
& COV & 0.054 & 0.047 & 0.092 & 0.107 \\
\hline \multirow{2}{*}{ Duplex } & Mean & 0.85 & 0.71 & 0.96 & 0.96 \\
& COV & 0.079 & 0.085 & 0.129 & 0.165 \\
\hline \multirow{2}{*}{ All exp. } & Mean & 0.85 & 0.68 & 0.84 & 0.81 \\
& COV & 0.091 & 0.102 & 0.096 & 0.135 \\
\hline \multirow{2}{*}{ All FE } & Mean & 0.88 & 0.74 & 0.95 & 0.96 \\
& COV & 0.068 & 0.064 & 0.099 & 0.127 \\
\hline \multirow{2}{*}{ ALL } & Mean & 0.87 & 0.73 & 0.93 & 0.93 \\
& COV & 0.071 & 0.085 & 0.106 & 0.142 \\
\hline
\end{tabular}

\section{CROSS-SECTIONS SUBJECTED TO COMBINED LOADING}

AISI-S100-12 [5] does not provide specific expressions based on the DSM for the design of crosssections subjected to combined loading. Rather, the general interaction equation is applicable with the compression and bending resistances calculated separately according to the DSM. However, as mentioned in Section 3.4, an alternative DSM-based approach has been proposed for cross-sections subjected to combined loading conditions. This method has been adapted from the method proposed by Rasmussen [14] for beam-columns and the assessment of the proposed approach is presented in this section. On the basis of the conclusions presented in the previous section regarding stainless steel RHS and SHS beams, the bending moment capacity $\mathrm{M}_{\mathrm{n}}$ obtained by considering inelastic strength reserve calculated with the compression strain factor $\mathrm{C}_{\mathrm{y}}$ proposed in AS/NZS4673 [2] and SEI/ASCE 8-02 [3] has been implemented in the analysis by replacing $M_{y}$ with $M_{n}$ in Eq. (9). Figure 6 presents the assessment of the proposed method for stainless steel cross-sections subjected to combined compression and uniaxial bending by plotting the normalized experimental and numerical resistance ratios $r_{u} / r_{y}$ against the corresponding generalized slenderness $\lambda_{n}$. The enhanced material property curves presented correspond to the average $\sigma_{\mathrm{u}} / \sigma_{0.2}$ ratios of the experimental specimens and the DSM strength curve for carbon steel cross-sections. 


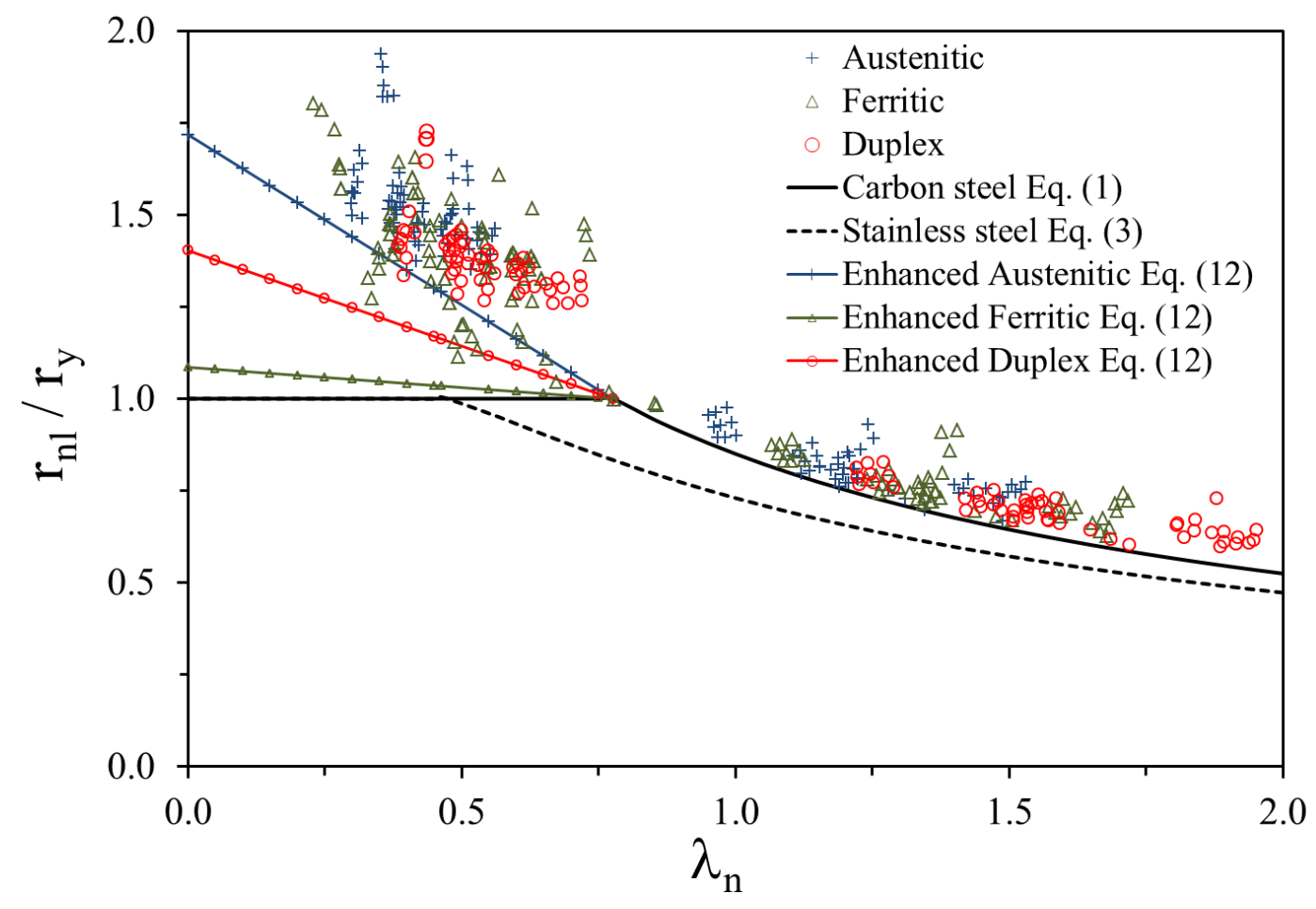

Figure 6. Assessment of DSM approach for stainless steel cross-sections under uniaxial combined loading considering linear interaction in yielding.

Figure 6 suggests that the local strength buckling curve for carbon steel cross-sections accurately predicts the combined loading strength of slender cross-sections, and that the strength curve is conservative over the full slenderness range when applied to stainless steel cross-sections. Regarding stocky cross-sections, it is evident that the consideration of the enhanced material properties introduces important improvement on the ultimate strength predictions when compared to the yield capacity $\left(r_{n l} / r_{y}=1\right)$, but is still conservative. The conservatism in the low slenderness range is higher than for the compression and bending moment loading cases investigated in previous sections due to the assumption made in Eq. (9) where a linear interaction is applied to determine the yield capacity of the cross-section. The linear interaction is usually accurate for slender cross-sections, but becomes increasingly conservative as the local slenderness decreases.

The influence of the interaction approach assumed for calculating the yield capacity under combined loading has been analysed by considering the interaction expression provided in EN1993-1-1 [46] for Class 1 and 2 cross-sections, presented in Eq. (16), where a plastic response of the cross-section is allowed in the calculation of the reduced bending moment capacity $M_{n, \text { red }}$. In using Eq. (16), $P_{\text {oy }}$ is 
calculated as shown in Eq. (17) and the parameter $a=a_{w}=(A-2 b t) / A$ needs to be considered when calculating the major axis strength, while for minor axis bending $a=a_{f}=(A-2 h t) / A$ is used, where $b$ and $\mathrm{h}$ are the internal width and height respectively. This interaction expression is considered as are the enhanced material properties in order to obtain accurate predictions of the ultimate strength of stocky cross-sections under combined loading. However, it is important to note that this interaction expression should only be applied to those cross-sections with a local buckling slenderness lower than 0.776, while for more slender cross-sections the linear interaction equation presented in Eq. (9) should be used.

$$
\begin{gathered}
\mathrm{M}_{\mathrm{n}, \text { red }}=\mathrm{M}_{\mathrm{n}} \frac{1-\mathrm{P}_{\mathrm{oy}} / \mathrm{P}_{\mathrm{y}}}{1-0.5 \mathrm{a}} \\
\mathrm{P}_{\mathrm{oy}}=\left[\frac{\mathrm{e}(1-0.5 \mathrm{a})}{\mathrm{M}_{\mathrm{n}}}+\frac{1}{\mathrm{P}_{\mathrm{y}}}\right]^{-1}
\end{gathered}
$$

Results based on Eqs. (16-17) corresponding to the DSM proposal $r_{\text {DSM }}$ for stocky cross-sections subjected to combined loading have been compared with those obtained from the different standards [1-3], viz. $\mathrm{r}_{\mathrm{EN}}$ for EN1993-1-4 [1] provisions and $\mathrm{r}_{\mathrm{AS} / \mathrm{SEI}}$ representing AS/NZS4673 [2]-SEI/ASCE 8-02 [3] specifications. Alternative design methods based on the CSM compression and bending capacities and the interaction expressions given in EN1993-1-1 [46] that also consider enhanced material properties and proposed by [24] and [47] have also been included in the analysis, referred to as $r_{\text {CSM }}$. Table 10 presents the predicted-to-experimental resistance ratios $r_{\text {pred }} / r_{u}$ for stocky cross-sections under combined loading, showing that the best capacity predictions are provided by the approaches considering strain hardening effects while conservative results are obtained for the current codified expressions. According to the results presented in Table 10, the DSM approach developed by adapting the procedure given in [14] provides excellent predictions of the ultimate capacity of stainless steel hollow sections subjected to combined compression and bending. Table 10 also demonstrates that among the codified design provisions, the best results are obtained for the EN1993-1-4 [1] specification since a nonlinear interaction curve is considered while results are less accurate for AS/NZS4673 [2] and SEI/ASCE 8-02 [3] which adopt a linear interaction equation. 
Table 10. Assessment of design approaches for stocky stainless steel cross-sections subjected to combined loading.

\begin{tabular}{ccccccc}
\hline \multirow{2}{*}{ Grade } & & $\mathrm{r}_{\text {DSM }} / \mathrm{r}_{\mathrm{u}}$ & $\mathrm{r}_{\text {DSM }} / \mathrm{r}_{\mathrm{u}}$ & $\mathrm{r}_{\text {CSM }} / \mathrm{r}_{\mathrm{u}}$ & $\mathrm{r}_{\mathrm{EN}} / \mathrm{r}_{\mathrm{u}}$ & $\mathrm{r}_{\text {AS/SEI }} / \mathrm{r}_{\mathrm{u}}$ \\
\hline \multirow{2}{*}{ CSustenitic } & Mean & 0.96 & 0.82 & 0.91 & 0.81 & 0.72 \\
& COV & 0.059 & 0.070 & 0.056 & 0.049 & 0.061 \\
\hline \multirow{2}{*}{ Ferritic } & Mean & 0.94 & 0.86 & 0.93 & 0.80 & 0.73 \\
& COV & 0.067 & 0.071 & 0.069 & 0.087 & 0.110 \\
\hline \multirow{2}{*}{ Duplex } & Mean & 0.93 & 0.84 & 0.91 & 0.88 & 0.76 \\
& COV & 0.051 & 0.098 & 0.072 & 0.047 & 0.045 \\
\hline \multirow{2}{*}{ All exp. } & Mean & 0.95 & 0.87 & 0.93 & 0.86 & 0.78 \\
& COV & 0.065 & 0.072 & 0.061 & 0.059 & 0.099 \\
\hline \multirow{2}{*}{ All FE } & Mean & 0.93 & 0.83 & 0.91 & 0.81 & 0.72 \\
& COV & 0.051 & 0.049 & 0.068 & 0.070 & 0.066 \\
\hline \multirow{2}{*}{ ALL } & Mean & 0.94 & 0.84 & 0.92 & 0.82 & 0.73 \\
& COV & 0.062 & 0.078 & 0.067 & 0.071 & 0.084 \\
\hline
\end{tabular}

Finally, design methods based on the effective width method are compared with the DSM approaches in Table 11 for slender cross-sections. The presented results suggest that the proposed DSM-based approach for combined loading based on the carbon steel strength curve provides least scattered and generally most accurate capacity predictions for the analysed data. The proposed approach is less accurate than the method codified in AS/NZS4673 [2] and SEI/ASCE 8-02 [3] on a means basis but the resistance of several specimens is overestimated by the later and the scatter is substantially greater for ferritic and duplex alloys.

Table 11. Assessment of design approaches for slender stainless steel cross-sections subjected to combined loading.

\begin{tabular}{clcccc}
\hline \multirow{2}{*}{ Grade } & & $\mathrm{r}_{\mathrm{DSM}} / \mathrm{r}_{\mathrm{u}}$ & $\mathrm{r}_{\mathrm{DSM}} / \mathrm{r}_{\mathrm{u}}$ & \multirow{2}{*}{$\mathrm{r}_{\mathrm{EN}} / \mathrm{r}_{\mathrm{u}}$} & $\mathrm{r}_{\mathrm{AS} / \mathrm{SEI}} / \mathrm{r}_{\mathrm{u}}$ \\
\hline \multirow{2}{*}{ Austenitic } & Mean & 0.89 & 0.78 & 0.85 & 0.96 \\
& COV & 0.059 & 0.073 & 0.127 & 0.042 \\
\hline \multirow{2}{*}{ Ferritic } & Mean & 0.91 & 0.80 & 0.82 & 0.94 \\
& COV & 0.060 & 0.063 & 0.159 & 0.126 \\
\hline \multirow{2}{*}{ Duplex } & Mean & 0.87 & 0.82 & 0.86 & 0.93 \\
& COV & 0.052 & 0.042 & 0.159 & 0.149 \\
\hline \multirow{2}{*}{ All exp. } & Mean & 0.94 & 0.79 & 0.75 & 0.84 \\
& COV & 0.002 & 0.087 & 0.101 & 0.118 \\
\hline \multirow{2}{*}{ All FE } & Mean & 0.88 & 0.81 & 0.85 & 0.95 \\
& COV & 0.060 & 0.048 & 0.152 & 0.115 \\
\hline \multirow{2}{*}{ ALL } & Mean & 0.89 & 0.80 & 0.84 & 0.94 \\
& COV & 0.060 & 0.061 & 0.153 & 0.118 \\
\hline
\end{tabular}

The assessment of the DSM approach proposed for the prediction of the resistance of stainless steel RHS and SHS subjected to combined loading is presented in Figure 7. The improvement achieved by using a more accurate interaction expression in the prediction of the ultimate resistance of stocky 
cross-sections is remarkable, especially seeing that for most of the ultimate strengths in the low slenderness range with apparent lower strength than the proposed strength curve, the comparison would be substantially improved if based on actual values of yield stress and ultimate tensile strength rather than the average values used to calculate the design strength curves shown in Figure 7 . It is evident that the proposed approach provides good estimation of the ultimate capacity of cross-sections subjected to combined loading for the full slenderness range.

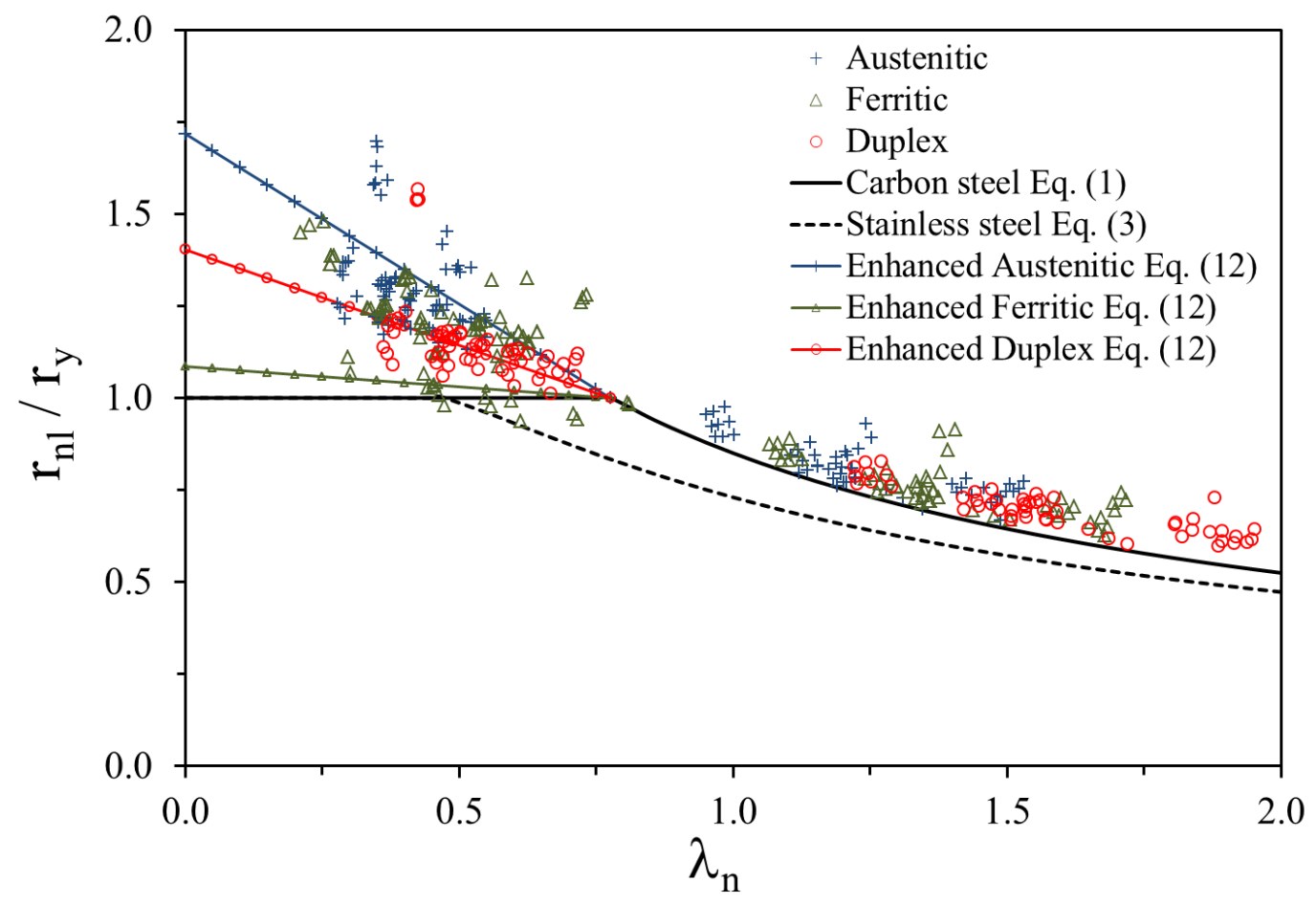

Figure 7. Assessment of the proposed DSM approach for stainless steel cross-sections under uniaxial combined loading.

\section{RELIABILITY ANALYSIS}

The reliability of the proposed full slenderness range DSM approach is assessed using a Load and Resistance Factor Design (LRFD) statistical analyses for stainless steel cross-sections subjected to different loading conditions. The procedure provided in Section F of the North American Specification AISI-S100-12 [5] has been followed and the statistical parameters corresponding to the material and geometrical variations of the different stainless steel grades analysed have been extracted from Afshan et al. [48]. The considered over-strength factors for the material yield strengths $\sigma_{0.2 \text { mean }} / \sigma_{0.2 \text {,min }}$ are 1.3 for austenitic stainless steel, 1.2 for ferritics and 1.1 for duplex and lean duplex grades, with COVs equal to $0.060,0.045$ and 0.030 respectively. $\sigma_{0.2 \text {,mean }}$ corresponds to the mean value produced by 
stainless steel manufacturers and $\sigma_{0.2, \min }$ to the minimum specified value in EN10088-4 [49]. The COV of the geometric properties was taken as 0.050 . The Australian and American standards prescribe resistance factors $\phi$ equal to 0.9 for tubular cross-sections in compression and bending and the target reliability index is $\beta=2.5$. In the calculation of the reliability indexes, the load data and factors from the Commentary of AS/NZS4600 [50] have been considered and a dead-to-live load ratio of 1/5 has been assumed.

Table 12 reports the calculated reliability indices for the full slenderness range DSM approach for austenitic, ferritic and duplex stainless steel RHS and SHS and for several resistance factors $\phi$. The mean and COV values for the test ultimate strength and predicted strength ratios $\mathrm{R}_{\mathrm{u}} / \mathrm{R}_{\text {pred }}$ are also reported for the different loading conditions in Table 12, since the ratios presented in Tables 6-11 correspond to $R_{\text {pred }} / R_{u}$ ratios. Considering the resistance factors $\phi$ prescribed in AS/NZS4673 [2] and SEI/ASCE 8-02 [3] equal to 0.9, the results shown in Table 12 demonstrate that the proposed approach can be safely applied to all the studied stainless steel grades and loading conditions since the calculated indices are higher than the target reliability index $\beta=2.5$. Since the high values of $\beta$ corresponding to $\phi=0.9$ suggest that higher value of $\phi$ can be used, the reliability indices assuming $\phi=0.95$ and $\phi=1.0$ have also been calculated and are reported in Table 12.

Table 12. Reliability calibration of the proposed full slenderness range DSM approach.

\begin{tabular}{|c|c|c|c|c|c|}
\hline $\begin{array}{l}\text { Loading } \\
\text { condition }\end{array}$ & & & Austenitic & Ferritic & $\begin{array}{l}\text { Duplex and } \\
\text { lean duplex }\end{array}$ \\
\hline \multirow{5}{*}{ Compression } & \multirow{2}{*}{$\mathrm{P}_{\mathrm{u}} / \mathrm{P}_{\text {pred }}$} & Mean & 1.09 & 1.04 & 1.07 \\
\hline & & $\mathrm{COV}$ & 0.087 & 0.043 & 0.078 \\
\hline & \multirow{3}{*}{$\begin{array}{c}\text { Reliability } \\
\text { indices } \beta\end{array}$} & $\phi=0.9$ & 3.43 & 3.09 & 2.75 \\
\hline & & $\phi=0.95$ & 3.31 & 2.84 & 2.52 \\
\hline & & $\phi=1.0$ & 3.09 & 2.61 & 2.29 \\
\hline \multirow{5}{*}{ Bending } & \multirow{2}{*}{$\mathrm{M}_{\mathrm{u}} / \mathrm{M}_{\text {pred }}$} & Mean & 1.08 & 1.08 & 1.13 \\
\hline & & $\mathrm{COV}$ & 0.088 & 0.068 & 0.080 \\
\hline & \multirow{3}{*}{$\begin{array}{c}\text { Reliability } \\
\text { indices } \beta\end{array}$} & $\phi=0.9$ & 3.38 & 3.17 & 2.99 \\
\hline & & $\phi=0.95$ & 3.25 & 2.93 & 2.76 \\
\hline & & $\phi=1.0$ & 3.03 & 2.71 & 2.53 \\
\hline \multirow{5}{*}{$\begin{array}{l}\text { Combined } \\
\text { loading }\end{array}$} & \multirow[b]{2}{*}{$r_{u} / r_{\text {pred }}$} & Mean & 1.07 & 1.08 & 1.10 \\
\hline & & $\mathrm{COV}$ & 0.062 & 0.069 & 0.054 \\
\hline & \multirow{3}{*}{$\begin{array}{c}\text { Reliability } \\
\text { indices } \beta\end{array}$} & $\phi=0.9$ & 3.46 & 3.19 & 2.96 \\
\hline & & $\phi=0.95$ & 3.35 & 2.96 & 2.72 \\
\hline & & $\phi=1.0$ & 3.11 & 2.73 & 2.49 \\
\hline
\end{tabular}




\section{CONCLUSIONS}

An extensive analysis of the cross-section behavior of austenitic, ferritic and duplex stainless steel RHS and SHS elements demonstrated that the adoption of an elastic-perfectly plastic material response results in overly conservative strength predictions since enhanced material properties are ignored. The same shortcoming was identified for the compression, bending and combined loading behavior of stainless steel cross-sections and members, particularly for alloys exhibiting pronounced strain hardening capacity, such as austenitic alloys, while for ferritic alloys, with low $\sigma_{\mathrm{u}} / \sigma_{0.2}$ ratios, the differences were less significant. In response, this paper presents an efficient full slenderness range Direct Strength Method approach for stainless steel hollow cross-sections that accounts for strain hardening and local buckling effects. The approach is based on the same strength curve for all different loading conditions and provides more accurate resistance predictions for all considered grades and loading situations than those obtained using existing codified expressions.

The proposed DSM approach is based on the strength curve for carbon steel structures given in AISIS100 [5,44] and the enhanced material property approach proposed by Rossi and Rasmussen [12]. Regarding the bending moment resistance of stainless steel RHS and SHS beams, the best predictions are obtained when the inelastic reserve strength is estimated based on the compression strain factor $\mathrm{C}_{\mathrm{y}}$ proposed in AS/NZS4673 [2] and SEI/ASCE 8-02 [3]. Finally, a new DSM approach that accurately predicts the ultimate capacity of stainless steel RHS and SHS subjected to combined loading through the same strength curve has been proposed using the DSM design method for beam-columns presented by Rasmussen [14]. This approach directly tackles the combined loading behaviour considering a local buckling slenderness based on the actual stress distribution and provides more accurate design strengths than traditional methods which consider the uncoupled combined loading problem.

This study develops and applies a comprehensive full slenderness range DSM methodology for stainless steel RHS and SHS members subjected to compression, bending and combined loading conditions. The methodology may be extended to different cross-section shapes in the future. 


\section{ACKNOWLEDGEMENTS}

The authors acknowledge the funding from the Ministerio de Economía y Competitividad (Spain) under Project BIA 2012-36373. The first author would also like to acknowledge the financial support provided by the Secretaria d'Universitats i de Recerca del Departament d'Economia i Coneixement de la Generalitat de Catalunya i del Fons Social Europeu through the FI-DGR 2014 grant.

\section{REFERENCES}

[1] Eurocode 3: Design of steel structures - Part 1-4: General rules - Supplementary rules for stainless steel. EN 1993-1-4, Brussels, Belgium, 2006.

[2] Australian/New Zealand Standard. Cold-formed stainless steel structures. AS/NZS 4673: 2001, Sydney, Australia, 2001.

[3] Specification for the Design of Cold-Formed Stainless Steel Structural Members. ASCE Standard SEI/ASCE 8-02, Reston, VA, American Society of Civil Engineers, 2002.

[4] Schafer B. and Pekoz T. Direct strength prediction of cold-formed steel members using numerical elastic buckling solutions. Thin-Walled Structures, Research and Developments, New York, Elsevier, 127-44, 1998.

[5] North American specification for the design of cold-formed steel structural members. American Iron and Steel Institute (AISI). S100-12, Washington, D.C., 2012.

[6] Becque J., Lecce M. and Rasmussen K.J.R. The direct strength method for stainless steel compression members. Journal of Constructional Steel Research, 64, 1231-1238, 2008.

[7] Niu S., Rasmussen K.J.R. and Fan F. Local-Global Interaction Buckling of Stainless Steel IBeams. II: Numerical Study and Design. Journal of Structural Engineering (ASCE), 141(8): $04014195,2015$.

[8] Huang Y. and Young B. Experimental and numerical investigation of cold-formed lean duplex stainless steel flexural members. Thin-Walled Structures, 73, 216-228, 2013.

[9] Huang Y. and Young B. Structural performance of cold-formed lean duplex stainless steel columns. Thin-Walled Structures, 83, 59-69, 2014. 
[10] Afshan S. and Gardner L. The continuous strength method for structural stainless steel design. Thin-Walled Structures, 68, 42-49, 2013.

[11] Bock M., Gardner L. and Real E. Material and local buckling response of cold-formed ferritic stainless steel sections. Thin-Walled Structures, 89, 131-141, 2015.

[12] Rossi B. and Rasmussen K.J.R. Carrying capacity of stainless steel columns in the low slenderness range. Journal of Structural Engineering (ASCE), 139, 1088-1092, 2013.

[13] Arrayago I., Rasmussen K.J.R and Real E. Full slenderness range DSM approach for ferritic stainless steel hollow cross-sections. Proceedings of The 8th International Conference on Steel and Aluminium Structures (ICSAS 2016). Hong Kong, China, 2016. Accepted for publication.

[14] Rasmussen K.J.R. Design of slender angle section beam-columns by the Direct Strength Method. Journal of Structural Engineering (ASCE), 132(2), 204-211, 2006.

[15] Talja A. and Salmi P. Design of stainless steel RHS beams, columns and beam columns. Research note 1619, VTT building technology, Finland, 1995.

[16] Liu Y. and Young B. Buckling of stainless steel square hollow section compression members. Journal of Constructional Steel Research, 59(2), 165-177, 2003.

[17] Young B. and Liu Y. Experimental investigation of cold-formed stainless steel columns. Journal of Structural Engineering (ASCE), 129(2), 169-176, 2003.

[18] Gardner L. and Nethercot D. A. Experiments on stainless steel hollow sections - Part 1: Material and cross-sectional behavior. Journal of Constructional Steel Research, 60(9), 1291-1318, 2004.

[19] Young B. and Lui W.M. Behaviour of cold-formed high strength stainless steel sections. Journal of Structural Engineering (ASCE), 131(11), 1738-1745, 2005.

[20] Rasmussen K. J. R. and Hancock G. J. Design of cold-formed stainless steel tubular members. I: Columns. Journal of Structural Engineering (ASCE), 119(8), 2349-2367, 1993.

[21] Gardner L., Talja A. and Baddoo N. R. Structural design of high-strength austenitic stainless steel. Thin-Walled Structures, 44(5), 517-528, 2006. 
[22] Zhao O., Rossi B., Gardner L. and Young B. Behaviour of structural stainless steel cross-sections under combined loading - Part I: Experimental study. Engineering Structures, 89, 236-246, 2015.

[23] Afshan S. and Gardner L. Experimental study of cold-formed ferritic stainless steel hollow sections. Journal of Structural Engineering (ASCE), 139(5), 717-728, 2013.

[24] Arrayago I. and Real E. Experimental study on ferritic stainless steel RHS and SHS crosssectional resistance under combined loading. Structures, 4, 69-79, 2015.

[25] Bock M., Arrayago I. and Real E. Experiments on cold-formed ferritic stainless steel slender sections. Journal of Constructional Steel Research, 109, 13-23, 2015.

[26] Zhao O., Rossi B., Gardner L. and Young B. Experimental and numerical studies of ferritic stainless steel tubular cross-sections under combined compression and bending. Journal of Structural Engineering (ASCE), 10.1061/(ASCE)ST.1943-541X.0001366, 04015110, 2015.

[27] Young B. and Ellobody E. Experimental investigation of concrete-filled cold formed high strength stainless steel tube columns. Journal of Constructional Steel Research, 62(5), 484-492, 2006.

[28] Young B. and Lui W. M. Tests on cold formed high strength stainless steel compression members. Thin-Walled Structures, 44(2), 224-234, 2006.

[29] Theofanous M. and Gardner L. Testing and numerical modelling of lean duplex stainless steel hollow section columns. Engineering Structures, 31(12), 3047-3058, 2009.

[30] Huang Y. and Young B. Material properties of cold-formed lean duplex stainless steel sections. Thin-Walled Structures, 54, 72-81, 2012.

[31] Real E. and Mirambell E. Flexural behaviour of stainless steel beams. Engineering Structures, 28(6), 926-934, 2005.

[32] Theofanous M, Saliba N, Zhao O, and Gardner L. Ultimate response of stainless steel continuous beams. Thin-Walled Structures, 83, 115-127, 2014.

[33] Zhou F. and Young B. Tests of cold-formed stainless steel tubular flexural members. Thin-Walled Structures, 43(9), 1325-1337, 2005. 
[34] Gardner L. and Nethercot D. A. Experiments on stainless steel hollow sections - Part 2: Member behaviour of columns and beams. Journal of Constructional Steel Research, 60(9), 1319-1332, 2004. [35] Rasmussen K. J. R. and Hancock G. J. Design of cold-formed stainless steel tubular members. II: Beams. Journal of Structural Engineering (ASCE), 119(8), 2368-2386, 1993.

[36] Arrayago I. and Real E. Experimental study on ferritic stainless steel simply supported and continuous beams. Journal of Constructional Steel Research, 119, 50-62, 2016.

[37] Theofanous M. and Gardner L. Experimental and numerical studies of lean duplex stainless steel beams. Journal of Constructional Steel Research, 66(6), 816-825, 2010.

[38] Hradil P. and Talja A. Investigating the role of gradual yielding in stainless steel columns and beams by virtual testing. Proceedings of The Fifth International Conference on Structural Engineering, Mechanics and Computation, 1459-1464, Cape Town, South Africa, 2013.

[39] Zhao O., Gardner L. and Young B. Behaviour and design of stainless steel SHS and RHS beamcolumns. Journal of Constructional Steel Research, (submitted for publication), 2015.

[40] Arrayago I., Real E. and Gardner L. Description of stress-strain curves for stainless steel alloys. Materials \& Design, 87, 540-552, 2015.

[41] Dawson R.G. and Walker A.C. Post-buckling of geometrically imperfect plates. Journal of the Structural Division (ASCE), 98(1), 75-94, 1972.

[42] Gardner L. and Nethercot D.A. Numerical modelling of stainless steel structural components - A consistent approach. Journal of Structural Engineering (ASCE), 130(10), 1586-1601, 2004.

[43] Shifferaw Y. and Schafer B.W. Inelastic bending capacity of cold-formed steel members. Journal of Structural Engineering (ASCE), 138(4), 468-480, 2012.

[44] Revised North American specification for the design of cold-formed steel structural members. American Iron and Steel Institute (AISI). S100-16, Washington, D.C., 2016.

[45] Schafer B. and Ádány S. Buckling analysis of cold-formed steel members using CUFSM: conventional and constrained finite strip methods. Proceedings of the 18th International Specialty Conference on Cold-formed Steel Structures, 39-54, 2006. 
[46] Eurocode 3: Design of steel structures - Part 1-1: General rules - General rules and rules for buildings. EN 1993-1-1, CEN. Brussels, Belgium, 2005.

[47] Zhao O., Rossi B., Gardner L. and Young B. Behaviour of structural stainless steel cross-sections under combined loading - Part II: Numerical Modelling and design. Engineering Structures, 89, $247-$ $259,2015$.

[48] Afshan S., Francis P., Baddoo N.R. and Gardner L. Reliability analysis of structural stainless steel design provisions. Journal of Constructional Steel Research, 114, 293-304, 2015.

[49] EN10080-4, Stainless steels part 4: Technical delivery conditions for sheet/plate and strip of corrosion resisting steels for construction purposes. European Committee for Standardization, 2009.

[50] Australian/New Zealand Standard. Cold-formed steel structures. AS/NZS4600: 2005. Sydney, Australia, 2005. 